\title{
MR Imaging of Non-Traumatic Intrinsic Brachial Plexus Neuropathy: Spectrum of Findings
}

\author{
Jyoti Sureka Panwar ${ }^{1^{\star}}$, Ravi Kanth Jakkani and Binu P Thomas ${ }^{2}$ \\ ${ }^{1}$ Department of Radiology, Christian Medical College, Vellore, Tamilnadu, India \\ ${ }^{2}$ Department of Hand \& Leprosy Reconstructive Surgery (HLRS), Christian Medical College and Hospital, Vellore, Tamil Nadu, India
}

\begin{abstract}
Objective: Non-traumatic intrinsic neuropathy of the brachial plexus (BP) could be because of focal or diffuse involvement. The purpose of this article is to focus on MR imaging spectrum and illustrate key features of a variety of pathologic entities based on review of 21 imaging studies. This paper highlights the detailed MR anatomy, the imaging techniques and the spectrum of MR imaging appearances of focal and diffuse form of non-traumatic intrinsic brachial neuropathy.
\end{abstract}

Materials and methods: We retrospectively reviewed 140 consecutive BP MR examinations performed at our institution over a period of four years from August 2006 to August 2010. We excluded cases of diverse clinical data including both traumatic and non-traumatic extrinsic compressive brachial neuropathies occuring along the course of the BP. Of 140 MR imaging studies of the BP, 75 were excluded and remaining 65 imaging studies were included for review. BP was assessed for the calibre, continuity, presence and distribution of signal changes (focal or diffuse) and focal masses.

Results: 21 of the 65 included imaging studies showed features of non-traumatic intrinsic BP neuropathy. The diagnosis was made on the basis of MR findings, electromyographic (EMG), clinical patient information and histopathological findings. The diagnosis included spectrum of neoplastic and non-neoplastic conditions like perineurioma, radiation plexitis, chronic inflammatory demyelinating polyneuropathy (CIDP) and hereditary motor sensory neuropathy (HMSN).

Keywords: Non-traumatic; Brachial plexus neuropathy; MRI

\section{Introduction}

Diagnosis of BP neuropathies is challenging as it is difficult to localize the lesion along the course of the plexus both clinically and on electrophysiological studies [1,2]. Advances in MRI techniques help in the precise localization and delineation of the perineural lesions from surrounding tissues with better contrast. Multiplanar capability and ability to differentiate nerves from vessels and surrounding soft tissues have made MRI the investigation of choice for evaluating BP pathologies [3].

\section{MR Imaging Protocol}

MR imaging was performed with a 1.5-Tesla MRI system (Magnetom Avanto, Siemens, Erlangen, Germany). Both cervical and body coils were used for all patients; surface coil was used to image the spinal cord and exiting nerve roots, while the body coil was used to image the plexus in the interscalene triangle and below it. All patients underwent T2-weighted sagittal (TR/TE msec of 4620/118 with a FOV of $25 \times 25 \mathrm{~cm})$ and axial $(1200 / 27,16 \times 23)$ (from C4-T3) imaging of cervical spine (Figure 1A and 1B), followed by coronal T1 (600/11, 25 $\times 35)$ and fat-suppressed T2-weighted imaging $(7880 / 63,25 \times 35)$ of BP (covered from $\mathrm{C} 1$ to $\mathrm{T} 4$ vertebrae in the craniocaudal plane and till the lateral margin of humeral head in the mediolateral plane), acquired in a plane parallel to the long axis of lower cervical vertebrae (Figure 1C). This was followed by oblique sagittal fat-suppressed T2 (4410/63, 25 $\times 35)$ and T1-weighted $(600 / 11,25 \times 35)($ covered medially from the spinal cord to the medial border of the humerus laterally) and axial fat-suppressed T2 $(4390 / 62,32 \times 32)$ and T1-weighted $(450 / 12,32$ $\times 32$ ) imaging (from C4-T3). The oblique sagittal images are exactly perpendicular to the long axis of nerve plexus (Figure 2A) while axial images are perpendicular to the long axis of cervical vertebrae in the coronal plane (Figure 3A). Initially, both $\mathrm{T} 1$ and fat-suppressed T2- weighted oblique sagittal imaging was done of the symptomatic side. Subsequently only fat-suppressed T2-weighted oblique sagittal imaging was done and $\mathrm{T} 1$ oblique sagittal imaging was reserved for clinically suspected cases of thoracic outlet syndrome, neoplastic conditions and non-neoplastic conditions like infections or radiation injury. In these conditions, both pre and post contrast fat-suppressed T1weighted sequences were obtained. A slice thickness of $3 \mathrm{~mm}$ with 0.3 mm interslice gap was used. A $320 \times 256$ matrix was used for the T1weighted images, and a $512 \times 256$ matrix for T2-weighted images.

\section{Normal Anatomy and MR Appearance of the Brachial Plexus}

The $\mathrm{BP}$ is formed by the ventral rami of $\mathrm{C} 5-\mathrm{T} 1$ nerve roots with or without minor contributions from $\mathrm{C} 4$ and $\mathrm{T} 2$ nerve roots. It is divided into 5 major components including roots, trunks, divisions, cords and terminal branches [4-6]. MRI is currently the imaging modality of choice for evaluation of BP [2]. Knowledge of normal MR appearance of $\mathrm{BP}$ is critical for identifying radiological abnormalities. Both $\mathrm{T} 1$ and fat-suppressed T2-weighted sequences optimally demonstrate the MR anatomy. Fat-suppressed T2-weighted sequence has the advantage of

*Corresponding author: Jyoti Sureka Panwar, MD, FRCR, Department of Radiology, Christian Medical College, Vellore, Tamilnadu, India, Tel: +919894584945; Fax: +9104162232035; E-mail: drjyoticmch@rediffmail.com

Received August 13, 2015; Accepted September 14, 2015; Published September 18,2015

Citation: Panwar JS, Jakkani RK, Thomas BP (2015) TMR Imaging of NonTraumatic Intrinsic Brachial Plexus Neuropathy: Spectrum of Findings. J Nucl Med Radiat Ther 5: 246. doi:10.4172/2155-9619.1000246

Copyright: @ 2015 Panwar JS, et al. This is an open-access article distributed under the terms of the Creative Commons Attribution License, which permits unrestricted use, distribution, and reproduction in any medium, provided the original author and source are credited. 
Citation: Panwar JS, Jakkani RK, Thomas BP (2015) TMR Imaging of Non-Traumatic Intrinsic Brachial Plexus Neuropathy: Spectrum of Findings. J Nucl Med Radiat Ther 5: 246. doi:10.4172/2155-9619.1000246
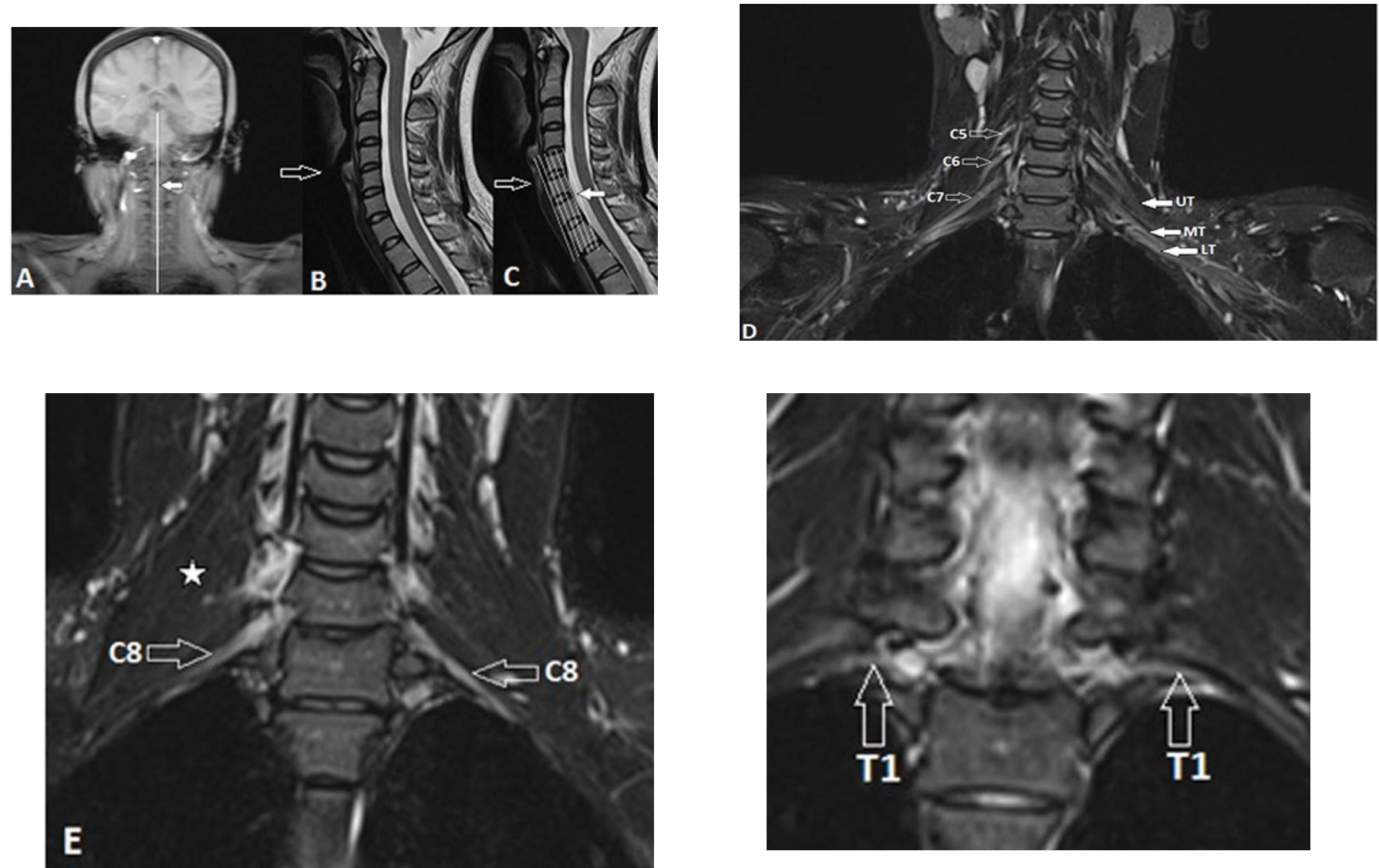

Figure 1: Normal MR imaging planes and appearance of BP. A-F, Acquisition of the coronal plane with fat-suppressed T2-weighted anterior (D), mid (E), and posterior $(F)$ coronal sections. First a coronal cervical spine scout is obtained $(A)$, based on this a sagittal T2-weighted spin-echo sequence of the cervical spine is acquired (B). Now based on this sagittal image, coronal fat-suppressed T2-weighted and T1-weighted sequences are obtained in a plane parallel to the long axis of the lower cervical vertebrae $(\mathrm{C})$ because the BP is oriented in an oblique coronal plane. On coronal fat-suppressed T2-weighted sequence, long axis of the nerve plexus is seen as elongated, uniform calibre, mildly hyperintense fascicular structure. On the anterior coronal image, normal C5, C6, C7 nerve roots (open arrows) are seen on the right side; on the left, the upper (UT), middle (MT) and lower trunks (LT) (solid arrows) are seen (D). At the level of middle scalene muscle (star), on the mid-section, C8 ventral ramus (open arrows) is seen bilaterally $(E)$, while the T1 nerve root (open arrows) is visualized completely on the posterior section ( $F$ )
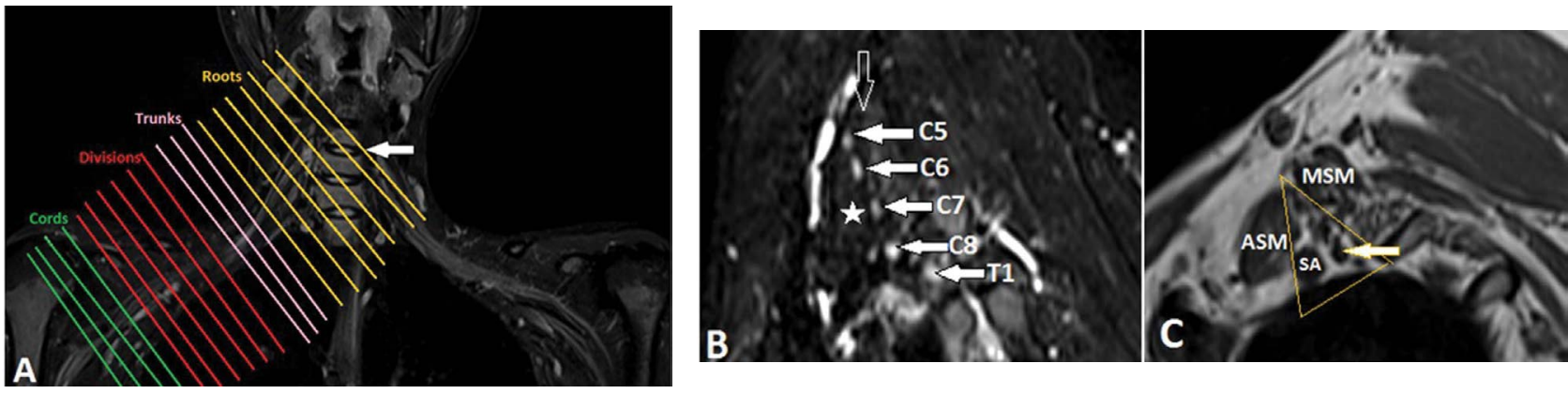

Figure 2A-2C: Normal MR imaging planes and appearance of BP. A-C, Acquisition of the oblique sagittal plane with fat-suppressed T2-weighted and T1-weighted images from medial to lateral show the normal segmental anatomy of BP. The coronal plane is used to plan oblique sagittal images, the oblique sagittal images are acquired perpendicular to the long axis of the plexus from spinal cord to the medial border of head of the humerus (A) depicting the cross-section of the plexus more accurately than true sagittal imaging. The nerve plexus is seen as uniform calibre of small, slightly hyperintense on fat-suppressed T2-weighted and isointense rounded structure on T1-weighted images. At the level of interscalene triangle, oblique sagittal fat-suppressed T2-weighted (B) image shows the ventral rami (white arrows) from C5 to T1 in between the anterior scalene muscle (star) anteriorly and middle scalene muscle (open arrow) posteriorly, on T1-weighted (C) image, these nerve roots (arrow), are seen in the interscalene triangle (as shown) in between the anterior (ASM) and middle (MSM) scalene muscles and superior to subclavian artery (SA). 
Citation: Panwar JS, Jakkani RK, Thomas BP (2015) TMR Imaging of Non-Traumatic Intrinsic Brachial Plexus Neuropathy: Spectrum of Findings. J Nucl Med Radiat Ther 5: 246. doi:10.4172/2155-9619.1000246

Page 3 of 10

detecting subtle changes in the calibre and signal intensity of nerves thereby precisely detecting intra and perineural pathology [1]. As the course of BP is oriented in the coronal plane, coronal and sagittal plane imaging are ideal to demonstrate MR anatomy [7]. The coronal plane is reliable for visualizing $\mathrm{BP}$ along its long axis (Figure $1 \mathrm{D}-1 \mathrm{~F}$ ). The oblique sagittal plane is perpendicular to the long axis of the plexus, hence demonstrating the course of the plexus in cross-section. It is the most reliable imaging plane for the visualization of the roots, trunks, divisions, cords, and branches of the BP (Figures 2B-2I). A normal nerve is round or ovoid in shape on cross section with linear, uniform, distinctive internal fascicular architecture on both the coronal and transverse imaging. On fat-suppressed T2-weighted sequence, the nerve plexus appears as uniform, mildly hyperintense fascicles interspersed with hypointense, fibrofatty connective tissue. Iso to hypointense fascicles within the hyperintense fibrofatty connective tissue may be seen on T1-weighted images [1]. Axial sequence has advantage of depicting the both pre and postganglionic portion of nerve roots as they are exiting from neural foraminae (Figure 3B).

\section{MR Imaging of non-traumatic intrinsic brachial plexus neuropathy}

This may be caused by a focal or a more diffuse pathology.

\section{Focal form of brachial neuropathy can be neoplastic or non- neoplastic in etiology}

Evaluation of patients with suspected focal involvement of the BP should include both oblique sagittal and coronal imaging with or without fat-suppressed post contrast T1-weighted sequence to delineate the exact site and extent of involvement (Table 1).

\section{Primary Neoplasm of BP}

Primary neoplasm of the BP are uncommon include neurogenic tumours, such as neurofibroma, schwannoma, malignant myxoid sarcoma and rarely intraneural synovial sarcoma. Non-neural sheath tumours include lipomas, ganglioneuromas, lymphangiomas and desmoids tumours [7-9].
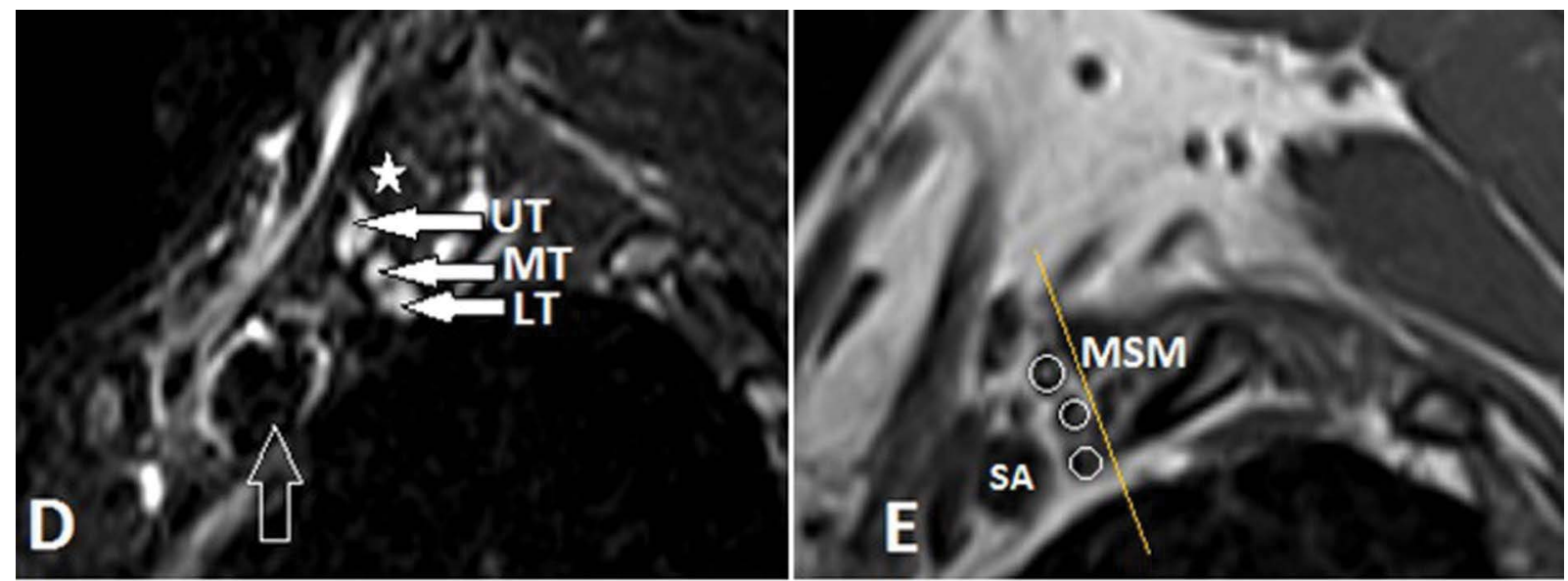

Figure 2D and 2E: Normal MR imaging planes and appearance of BP. D-E, At the level of lateral margin of MSM (star), oblique sagittal fat-suppressed T2-weighted (D) and T1-weighted $(E)$ image show the formation of three trunks (UT-upper trunk, MT-middle trunk and LT-lower trunk) (white arrows on right, and circles on left), superior to subclavian vessels (open arrow, SA) and at lateral margin of MSM (yellow line), where most of the portion of anterior scalene muscle has already ended.
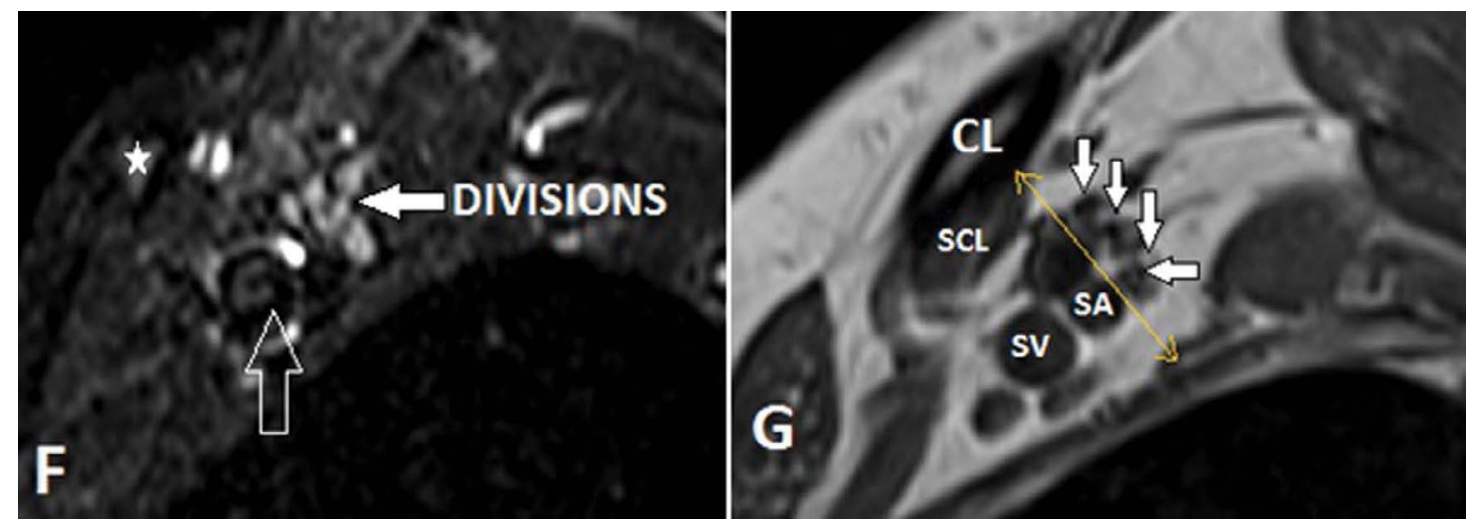

Figure 2F and 2G: Normal MR imaging planes and appearance of BP. F-G, At the level of crossing of clavicle (star, CL) in the costoclavicular space (yellow line in between the $C L$ and first rib), oblique sagittal fat-suppressed T2-weighted (F) and T1-weighted (G) image show the multiple nerve plexus as divisions (white arrows), superior to subclavian vessels (open arrow, SA-subclavian artery and SV-subclavian vein), CL- clavicle, SCL- subclavius muscle. 
Citation: Panwar JS, Jakkani RK, Thomas BP (2015) TMR Imaging of Non-Traumatic Intrinsic Brachial Plexus Neuropathy: Spectrum of Findings. J Nucl Med Radiat Ther 5: 246. doi:10.4172/2155-9619.1000246
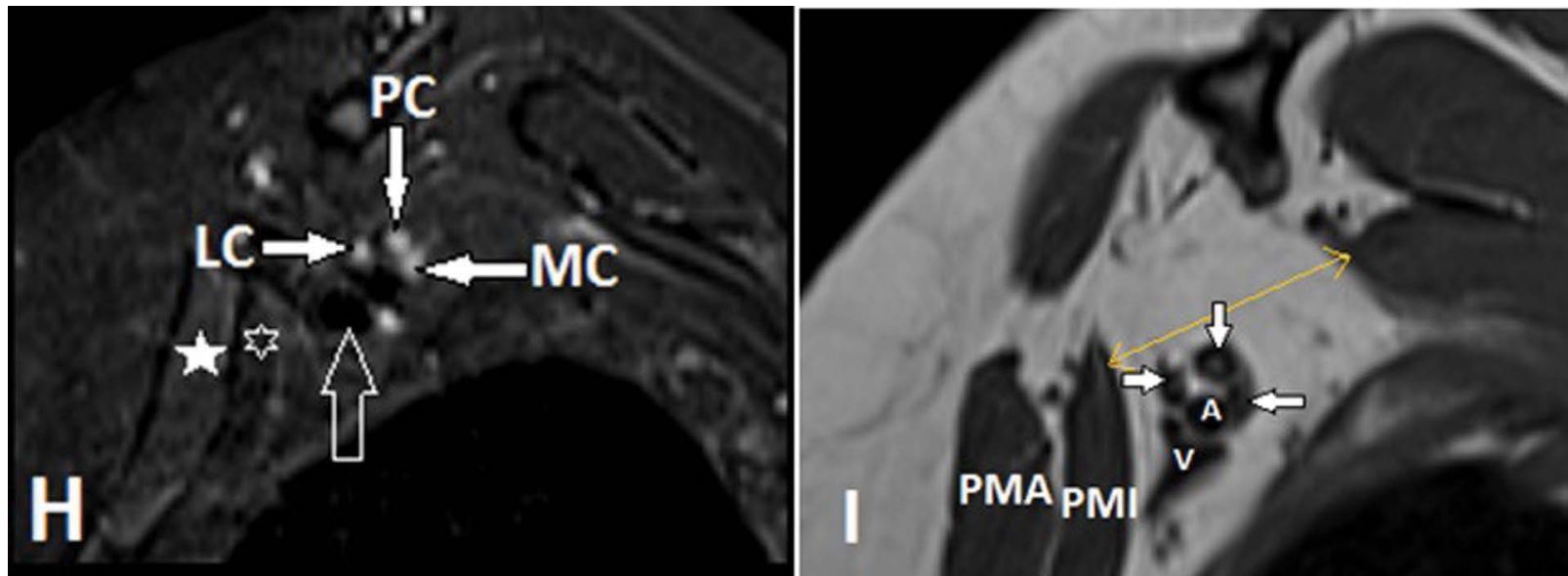

Figure 2H and 2I: Normal MR imaging planes and appearance of BP. H-I, At the level of pectoralis muscles, major (PMA) (solid star) and minor (PMI) (open star) in retropectoralis minor space (yellow line in between the PMI and anterior chest wall) and lateral to the first rib where the subclavian vessels have become the axillary vessels (open arrow). Oblique sagittal fat-suppressed T2-weighted (F) and T1-weighted (G) images show the three cords (white arrows), lateral cord (LC) is anterior, posterior cord $(\mathrm{PC})$ is superior, and medial cord $(\mathrm{MC})$ is posterior to the axillary artery $(\mathrm{A})$ and vein $(\mathrm{V})$.
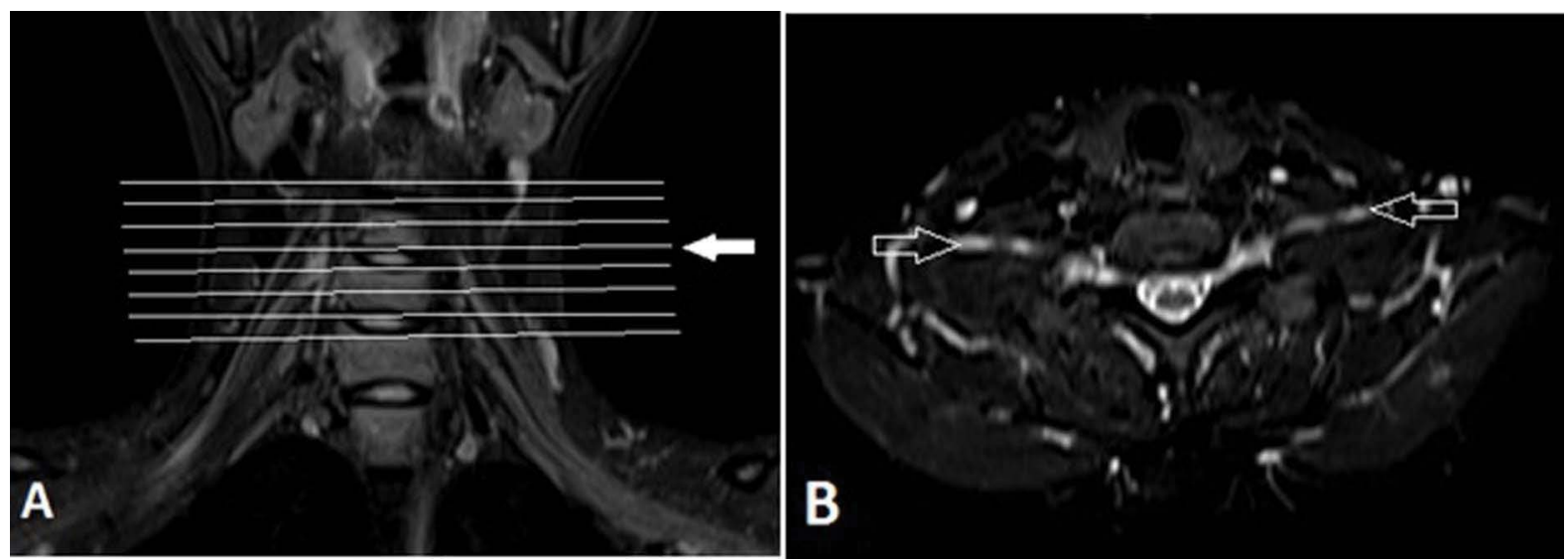

Figure 3: Normal MR imaging planes and appearance of brachial plexus. A-B, Acquisition of the axial plane. The coronal plane is also used to plan axial images the axial images are acquired perpendicular to the long axis of the cervical vertebrae from C4 to T3 (A) depicting the nerve roots as they exit from neural foraminae as seen here on fat-suppressed T2-weighted image (B).

MRI can differentiate neurofibroma from schwannoma, a distinction crucial for surgical planning [1]. On MRI, neurofibroma is fusiform in shape and is present within the nerve substance in a longitudinal orientation without a definite capsule. Hence it is difficult to resect these lesions without damaging the nerve [9-11]. On the other hand, schwannomas arise from schwann cells and tend to grow eccentrically, with displacement of nerve fibres around the lesion, making it easier to remove the tumour without sacrificing the nerve [9-12]. The "target sign" with peripheral high signal and central low signal intensity on T2-weighted images is more commonly seen in neurofibroma, though it may also be seen in schwannoma (Figure 4). The "fascicular sign" (salt and pepper appearance on T2-weighted images) is common in schwannoma [9-13].

The malignant myxoid sarcoma of the peripheral nerve is also known as malignant peripheral nerve sheath tumour (MPNST) $[9,13]$. They can occur either spontaneously or in association with neurofibromatosis-1 (NF1) [14]. On MR, it is often seen as a fusiform lesion, located centrally within the nerve in a longitudinal orientation like a benign neurogenic tumour (Figure $5 \mathrm{~A}$ ). However, large size ( $>5$ $\mathrm{cm}$ ), invasion of fat planes, heterogeneity due to areas of hemorrhage and necrosis, ill-defined margins without capsule and edema surrounding the lesion favor a diagnosis of malignant sarcoma (Figure 5B) [13].

A synovial sarcoma arising within a spinal nerve root or a peripheral nerve is very unusual [15-17]. On MR, intraneural synovial sarcoma is often misdiagnosed as schwannoma or MPNST [18]. This is because a fluid-fluid level (Figure 6) within the lesion can be seen in intranueral synovial sarcoma like in the case of schwannoma. It is difficult to characterize this lesion on imaging hence histopathology and cytogenetic testing is required for definitive diagnosis [15-17].

\section{Secondary Tumours Involving the BP}

Secondary malignant tumours affecting the BP tend to present as diffuse involvement of the entire plexus though occasionally a more focal lesion may be seen. They usually originate from the breast or lung cancers [1]. 
Citation: Panwar JS, Jakkani RK, Thomas BP (2015) TMR Imaging of Non-Traumatic Intrinsic Brachial Plexus Neuropathy: Spectrum of Findings. J Nucl Med Radiat Ther 5: 246. doi:10.4172/2155-9619.1000246

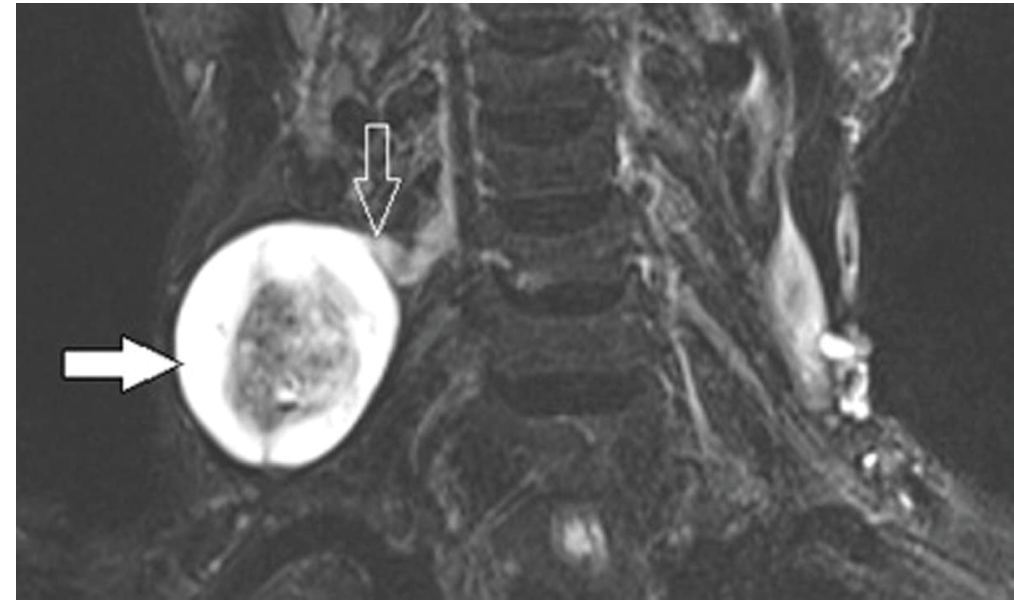

Figure 4: A 75-year-old male with schwannoma. Coronal fat-suppressed T2-weighted MR image shows a rounded mass with central low signal and peripheral high signal intensity (target sign) (solid arrow) along the C5 postganglionic spinal nerve root with a well defined hypointense capsule. Note the nerve (open arrow) is eccentric in relation to the mass.

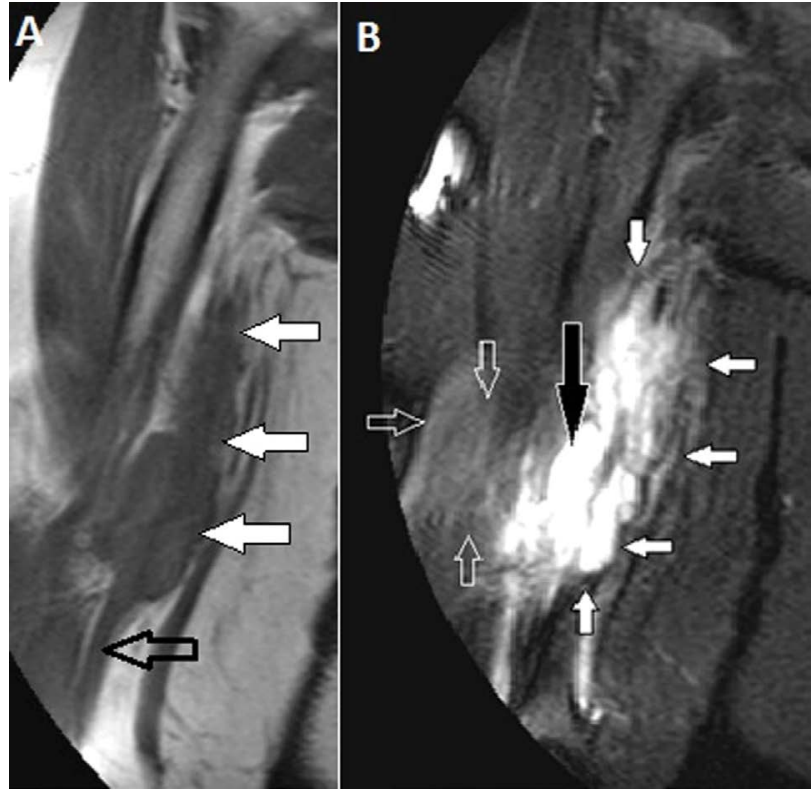

Figure 5: A 30-year-old male with malignant myxoid sarcoma of the median nerve. A, Coronal T1-weighted MR image shows a large elongated mass located centrally (white arrows) along the median nerve (open arrow) and infiltrates the nerve. B, Coronal fat-suppressed T2-weighted MR image shows a large heterogeneous mass with ill-defined margins (white arrows), cystic changes (black arrow) and edema surrounding it (open arrows).

\section{Isolated Intraneural Metastasis}

Focal intra or perineural metastasis are uncommon and can mimic the primary BP neoplasm, history of known malignancy aids the diagnosis. They tend to cause focal enlargement of the nerve plexus (Figure 7A and 7B) [18]. The criteria for diagnosing a true isolated metastatic deposit in peripheral nerve is absence of tumour in the soft tissues in the close vicinity of the involved nerve trunk, absence of regional lymphadenopathy, and no previous surgical manipulation of the involved area [18]. Focal involvement of BP can occur secondary to intra or perineural myelomatous deposit (Figure $8 \mathrm{~A}$ and $8 \mathrm{~B}$ ) without contiguous involvement of vertebrae or paravertebral component. It

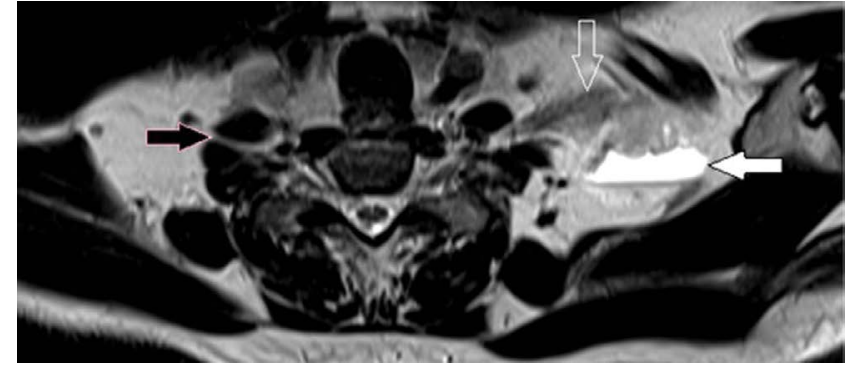

Figure 6: A 68-year-old male with intraneural synovial sarcoma of BP. Axial T2-weighted MR image shows a mass arising from the left $C 7$ nerve root (open arrow) with central fluid-fluid level (solid arrow). Note the normal right C7 spinal root (black arrow) in between the anterior and middle scalene muscles.

is important to diagnose this isolated peripheral nerve metastasis as recent advances in imaging technology allow for chemotherapeutic agents to be placed within the subepineurium of peripheral nerve for targeted neuroablation of the nerves [19].

\section{Localized Infiltration of BP by Contiguous Spread}

BP is commonly involved by contiguous spread from primary malignancy like breast and lung cancers [20]. These deposits are generally unilateral and can give rise to focal enlargement of the plexus element owing to infiltration. In breast malignancy, soft tissue in the postoperative bed or superior sulcus, axillary node or adjacent bony metastasis can cause contiguous infiltration of the BP [20]. Nodal metastasis can give rise to extracapsular spread with infiltration of adjacent pectoralis muscles and cords of the plexus (Figure 9). Likewise, Pancoast or superior sulcus tumour can invade the adjoining soft tissue and cause focal infiltration of lower roots of the BP (Figure 10) $[21,22]$. These patients usually present with severe, unrelenting shoulder and arm pain along the distribution of the $\mathrm{C} 8$ and $\mathrm{T} 1$ nerve trunks together with Horner's syndrome [21]. Identification of focal involvement in MR imaging is helpful for selecting patients suitable for local surgical resection [22]. 
Citation: Panwar JS, Jakkani RK, Thomas BP (2015) TMR Imaging of Non-Traumatic Intrinsic Brachial Plexus Neuropathy: Spectrum of Findings. J Nucl Med Radiat Ther 5: 246. doi:10.4172/2155-9619.1000246

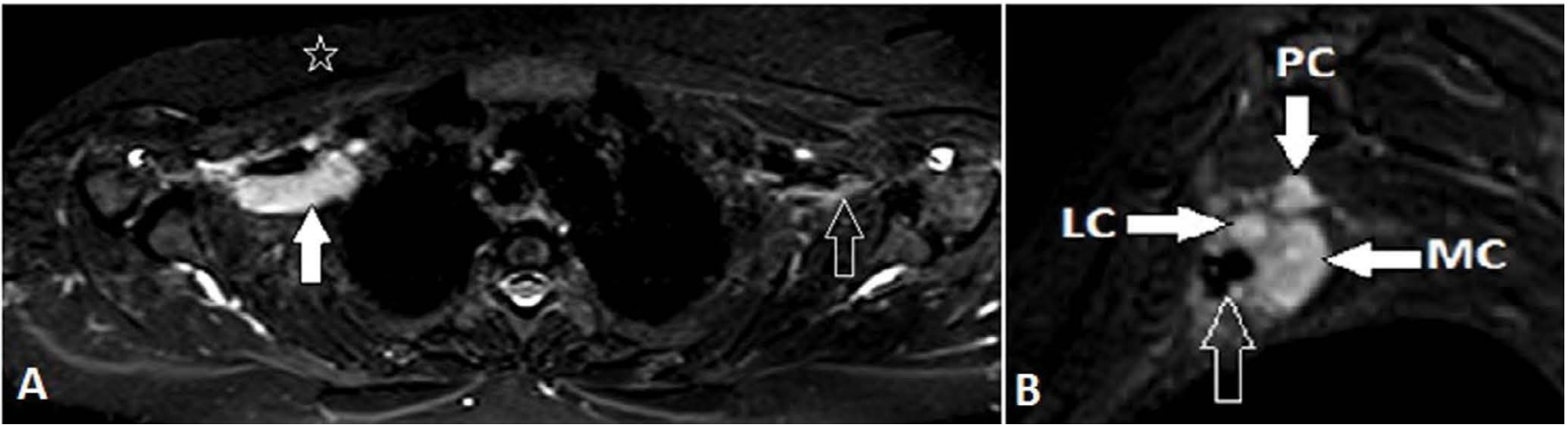

Figure 7: A 57-year-old female, known case of postoperative and post radiotherapy carcinoma right breast with isolated intraneural metastasis. A, Axial fatsuppressed T2-weighted MR image shows isolated thickening and abnormal high signal of cords of the BP (white arrow) on right side. Note the normal left cords of plexus (open arrow). No residual or recurrent soft tissue in the post-operative bed (star). B, oblique sagittal fat-suppressed T2-weighted MR image better demonstrates the exact thickening and abnormal high signal of the cords of the brachial plexus (white arrows) in close proximity to the axillary vessels (open arrow).
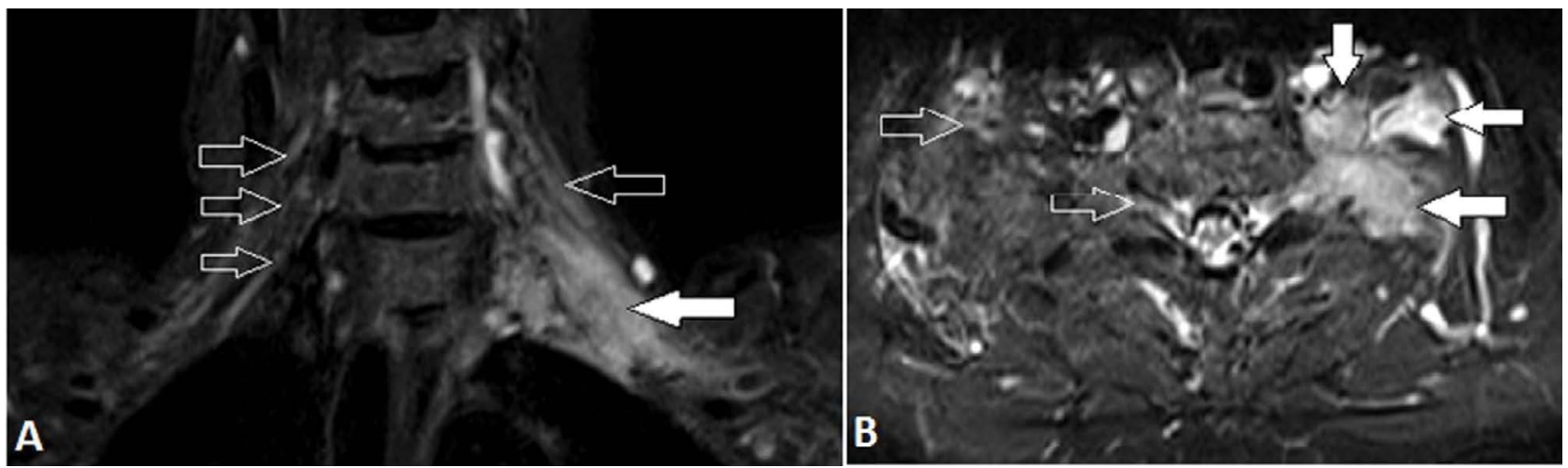

Figure 8: A 67-year-old male, known case of multiple myeloma with isolated intraneural myelomatous deposits. A, Coronal and B, Axial fat-suppressed T2weighted MR images show isolated marked thickening and abnormal high signal of the lower BP (white arrow) on left side. Note the uninvolved normal right and left upper BP (open arrows). No abnormal signal intensity in the visualized vertebra.

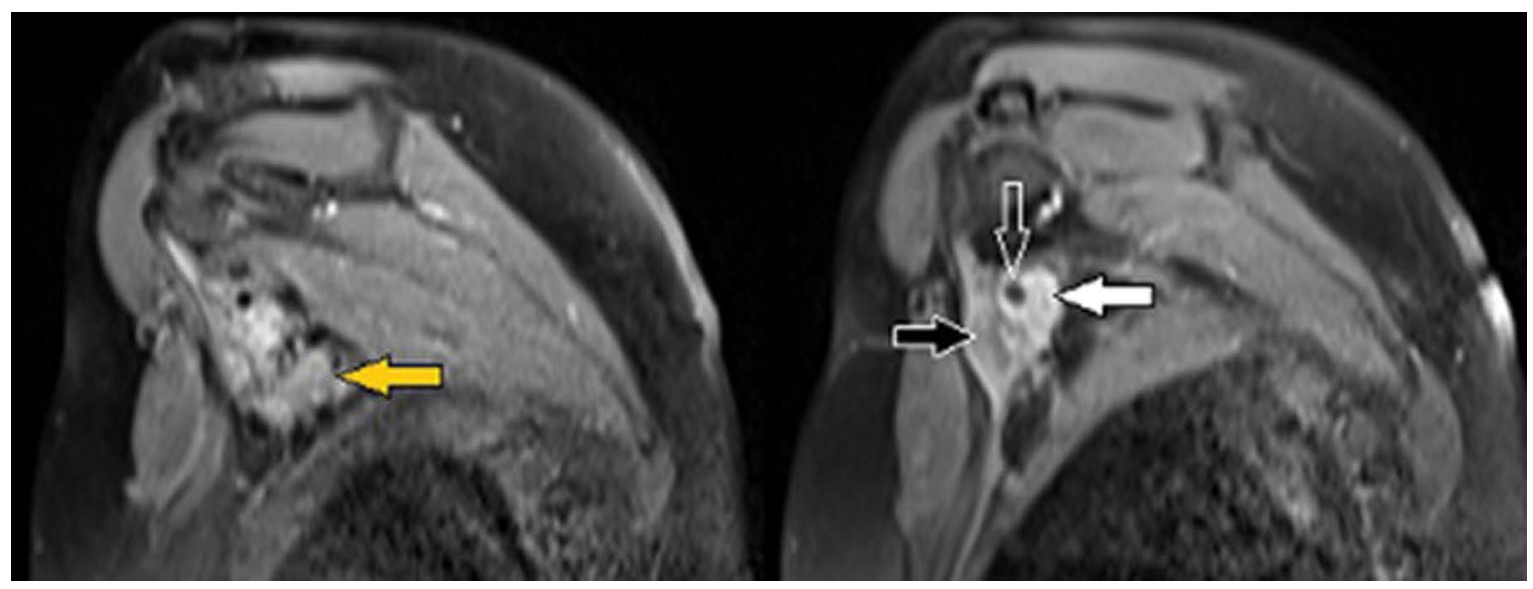

Figure 9: A 54-year-old female on follow up for carcinoma right breast with focal infiltration of BP by contiguous spread from metastatic axillary adenopathy. Oblique sagittal fat-suppressed post contrast T1-weighted contiguous MR images show multiple enhancing axillary nodal metastasis (yellow arrow) with extracapsular spread and infiltration of pectoralis minor muscle (black arrow). There is also encasement of axillary vessels (open arrow) and infiltration of the cords of the BP (white arrow). 


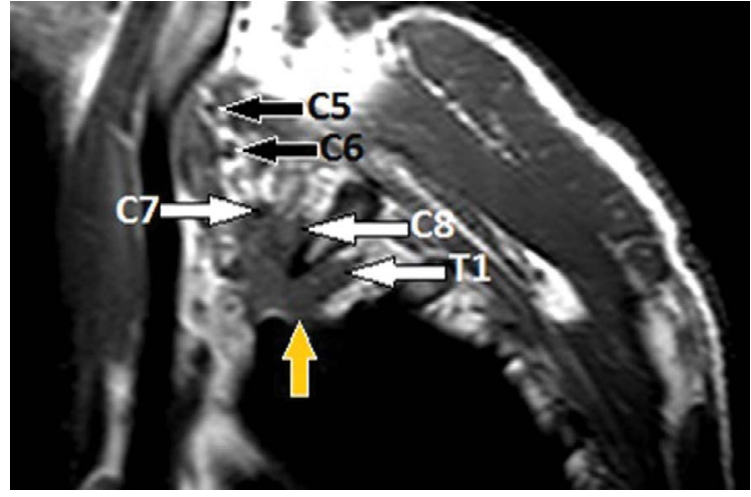

Figure 10: A 52-year-old male with focal infiltration of BP by contiguous spread from Pancoast tumour. Oblique sagittal T1-weighted MR image shows an isointense mass in the right lung apex (yellow arrow) extending to encase the right $\mathrm{C} 7, \mathrm{C} 8$ and $\mathrm{T} 1$ nerve roots (white arrows). Note the uninvolved $\mathrm{C} 5$ and $\mathrm{C} 6$ nerve roots of the BP (black arrows).

\section{Non-neoplastic Focal Intrinsic Involvement of BP}

Perineurioma and focal form of CIDP are uncommon causes of localized hypertrophy of BP or peripheral nerve. Intraneural perineurioma is also known as localized hypertrophic neuropathy, a rare clinical entity found in children [23]. MR imaging helps in the identification and accurate localization of the lesion. Specific characterization may not be possible as the lesion demonstrates hypertrophy and non-specific T2-weighted hyperintensity which may be seen in any focal benign tumour [23]. Diagnosis is based mainly on histologic findings of replacement of normal architecture of the nerve by concentric whorls of perineural cells and aided by immunohistochemical profile [24].

CIDP is a generalized neuropathy which rarely presents in an asymmetric or focal form $[25,26]$. Focal thickening, abnormal signal intensity and enhancement observed on imaging which need to be correlated with clinical, electrophysiological findings and markedly elevated cerebrospinal fluid protein (CSF). Dramatic response to steroid and immunosuppressant drugs supports this diagnosis [27].

\section{Diffuse form of Non-traumatic Intrinsic Brachial Neuropathy}

Diffuse involvement can be neoplastic or non-neoplastic in origin. Non-neoplastic conditions include a wide range of inherited and acquired disorders like the various subtypes of HMSNs, CIDP and radiation induced plexopathy. Neoplastic disorders comprise of diffuse neurofibromatosis, leukemic, lymphomatous (perineural lymphomatosis), myelomatous and melanomatous infiltration of the BP. It also includes the diffuse metastatic plexus infiltration commonly from breast and lung malignancy.

\section{HMSN}

A group of inherited slowly progressive disorders affecting motor and sensory peripheral nerves, characterized by diffuse peripheral nerve enlargement with limb atrophy [28]. Most patients present in their first or second decade. On MR, variable fusiform enlargement of nerve roots or nerves with disruption of the internal fascicular architecture and homogeneous enhancement may be seen (Figure 11A) [29]. Affected muscles show acute or chronic denervation (fatty atrophy) changes

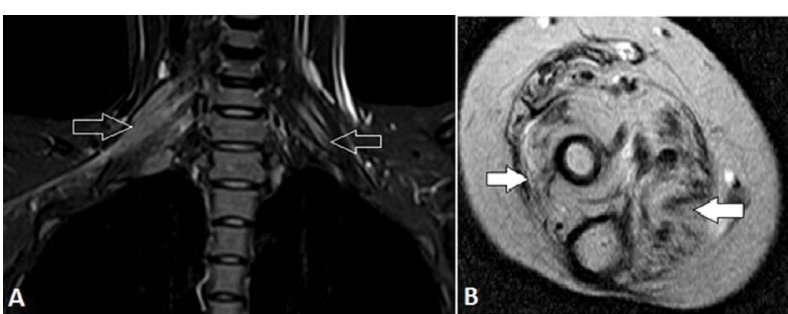

Figure 11: A 22-year-old female with hereditary motor sensory neuropathy (HMSN). A, Coronal fat-suppressed T2-weighted MR image shows marked asymmetric thickening and disruption of normal internal fascicular architecture of the BP; on the right, from root to cord level and on the left, mildly thickened upper trunk (arrows). B, Axial T2-weighted MR image at the level of right mid forearm shows marked atrophy with fatty replacement (arrows) of the muscles.

(Figure 11B). On imaging, this condition may often mimic CIDP and plexiform neurofibromatosis. Absence of inflammatory infiltrates and presence of "onion bulb" histology at sural nerve biopsy, molecular genetic testing along with positive family history, clinical-laboratory data, and nerve conduction studies distinguish HMSN from CIDP [29].

\section{CIDP}

It is an acquired, immune-mediated peripheral neuropathy, presents with relapsing and remitting motor and sensory loss in multiple limbs [30]. Most frequently, it is idiopathic but can be associated with several conditions like HIV, diabetes, inflammatory bowel disease, Sjogren's syndrome, lymphoma, IgM, IgG or IgA monoclonal gammopathy [30]. On MR, marked symmetrical enlargement and enhancement of the nerve roots and multiple cranial nerves may help to differentiate this entity from HMSN when the disease presents in early childhood (Figure 12A-12C) [30-32]. In addition to imaging, negative family history, are flexia on clinical examination, significant motor nerve conduction block on electrophysiological study, and persistently raised CSF protein can support the possibility of this acquired and potentially treatable disorder over the inherited HMSN.

\section{Radiation plexitis}

Incidence of radiation-induced BP injury has increased because of increasing trend towards conservative surgery and radiation therapy in the treatment of early-stage breast cancer. Likelihood of radiation plexopathy is closely related to dose of radiation received and concomitant use of chemotherapy. Radiation plexitis is a kind of subacute to chronic plexopathy with a delayed onset, 6 month to over 20 years post-radiation, with a peak onset at $10-20$ months $[1,20,33]$. Radiation-induced plexopathy presents early as compared to metastatic plexus lesions, and this may help to differentiate between the two $[34,35]$. Most patients present with sensory symptoms and weakness though intractable shoulder and arm pain as seen in metastatic plexopathy is usually not present [34]. On imaging, mild smooth diffuse thickening, T2 hyperintensity (Figure 13) and linear enhancement of upper BP without a focal mass favour radiation injury over metastatic malignancy. The upper BP (C5-7) is more commonly involved than the lower BP (C8, T1) $[20,33,35]$. Delayed radiation fibrosis can be differentiated from tumour infiltration by $\mathrm{T} 2$ fat-suppressed sequence, in which radiation fibrosis demonstrates low signal intensity on both $\mathrm{T} 1$ and T2 weighted images, whereas tumour shows high signal on T2 and low signal intensity on T1-weighted images [20]. 
Citation: Panwar JS, Jakkani RK, Thomas BP (2015) TMR Imaging of Non-Traumatic Intrinsic Brachial Plexus Neuropathy: Spectrum of Findings. J Nucl Med Radiat Ther 5: 246. doi:10.4172/2155-9619.1000246

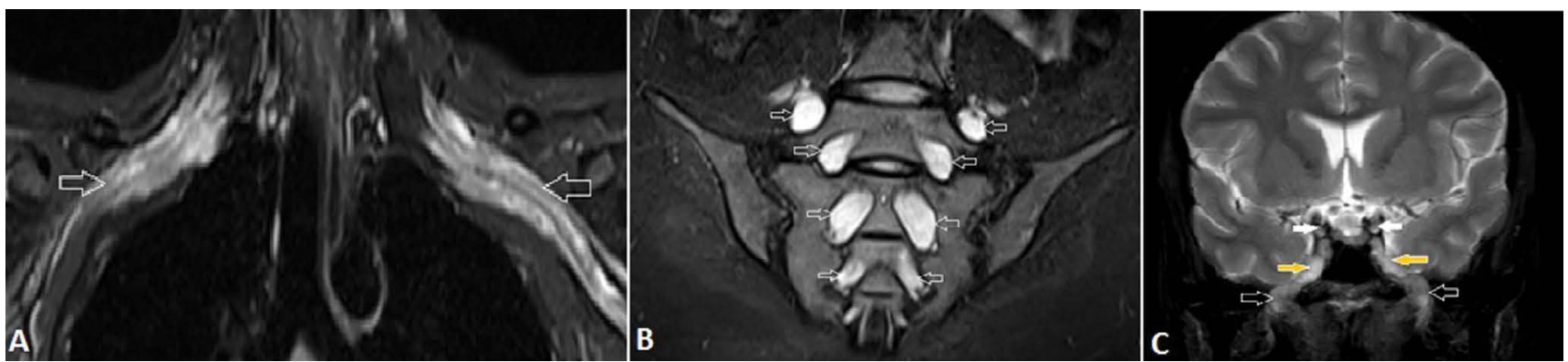

Figure 12: A 29-year-old female with chronic inflammatory demyelinating polyneuropathy (CIDP). A, Coronal fat-suppressed T2-weighted MR image shows bilateral symmetrically enlarged and hyperintense BP (arrows). B, Coronal fat-suppressed T2-weighted MR image shows diffuse marked symmetrical hypertrophy and abnormal high signal of the lumbosacral nerve roots (arrows). C, Coronal T2-weighted MR image of brain shows marked thickening of the cranial nerves in the lateral wall of cavernous sinus and foramen ovale. Note the enlarged oculomotor nerves (white arrows) and mandibular nerves (black arrows), coming out from Meckel's cave (yellow arrows) into the masticator space through the enlarged foramen ovale.

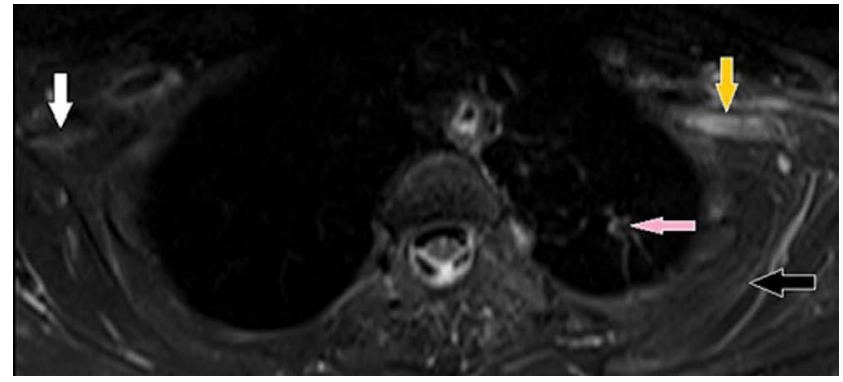

Figure 13: A 59-year-old female, known case of postoperative and post radiotherapy carcinoma of the left breast with radiation plexitis. Axial fat-suppressed T2-weighted MR image shows smooth, diffuse thickening and abnormal high signal of the left BP (yellow arrow) without focal nodularity. Note the normal calibre and signal of right BP (white arrow). Mild atrophy and subtle T2 hyperintensity of muscles around the left shoulder (black arrow) owing to subacute denervation. Mild volume loss with few fibrotic changes are also noted in the left upper lobe (pink arrow), possibly radiation induced changes

\section{Diffuse neurofibromatosis}

It may or may not be associated with NF-1. The tumours are usually multiple and vary in size. The lesions in diffuse neurofibromatosis are multifocal with smooth rounded contour, and seen along the course of peripheral nerves [36]. Rarely diffuse fusiform enlargement of nerves (Figure 14) may be seen.

\section{Perineural lymphomatosis}

It is also known as peripheral neurolymphomatosis (NL). These patients generally present with non-specific sensorimotor weakness $[37,38]$. Commonly, BP involvement occurs as a result of extrinsic compression by enlarged lymph nodes however direct infiltration of plexus by lymphoma is rarely seen [39]. It may occur in isolation or may be associated with systemic or primary CNS lymphoma [1]. Early diagnosis and treatment of NL may prevent considerable morbidity and mortality. Nerve plexus thickening, abnormal signal intensity and variable post gadolinium enhancement with associated soft tissue involvement on MR are commonly seen but not specific for NL (Figure $15 \mathrm{~A}$ and 15B). Possibility of this condition should be considered if a diffusely infiltrating plexus or peripheral nerve lesion is seen in a patient with lymphoma. Definitive diagnosis usually requires nerve biopsy [40].

\section{Perineural leukemic infiltration of BP}

Involvement of peripheral nervous system is rare and can be

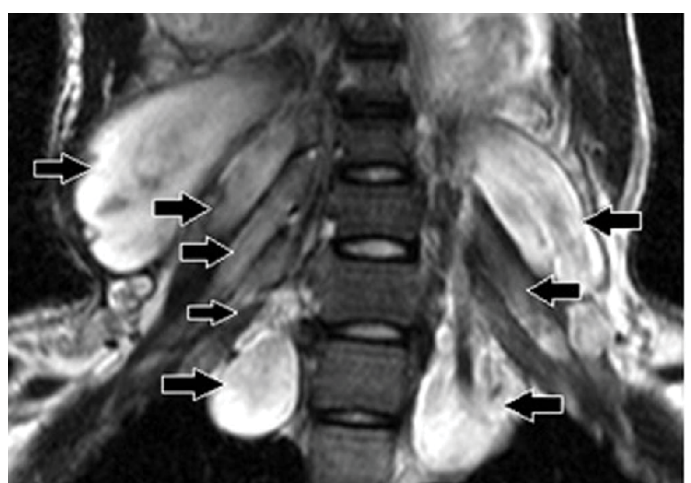

Figure 14: A 16-year-old male with neurofibromatosis type 1. Coronal fatsuppressed T2-weighted MR image shows diffuse, fusiform, longitudinally oriented hyperintense lesions involving all the pre and postganglionic cervical nerve roots (arrows) of BP bilaterally without any definite capsule.

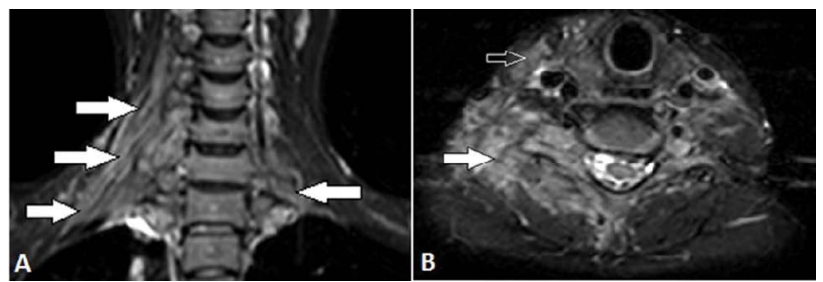

Figure 15: A 23-year-old female with perineural lymphomatosis. A, Coronal fat-suppressed T2-weighted MR image shows asymmetric thickening, hyperintensity and enhancement (not shown) along the BP (arrows). Note the clumping of plexus elements on the right side with loss of internal architecture. B, Axial fat-suppressed T2-weighted MR image shows high signal intensity in the sternocleidomastoid (open arrow), scalene and paraspinous muscles (white arrow) on the right side and adjacent soft tissue of the neck.

secondary to chemotherapy or leukemic infiltration. Chemotherapeutic drugs like Vincristine used for treatment of acute lymphocytic leukemia can cause neuropathy of a single peripheral nerve or the whole plexus [41]. This is often temporary and patients recover quickly after cessation of the causative drug. On imaging, denervation changes are usually noted in the muscles supplied by the involved nerves. Patients with leukemic infiltration to BP present with non-specific arm pain, weakness and numbness. On MR, perineural enhancing tissue along the plexus with loss of normal internal fascicular architecture suggest leukemic deposits 
Citation: Panwar JS, Jakkani RK, Thomas BP (2015) TMR Imaging of Non-Traumatic Intrinsic Brachial Plexus Neuropathy: Spectrum of Findings. J Nucl Med Radiat Ther 5: 246. doi:10.4172/2155-9619.1000246
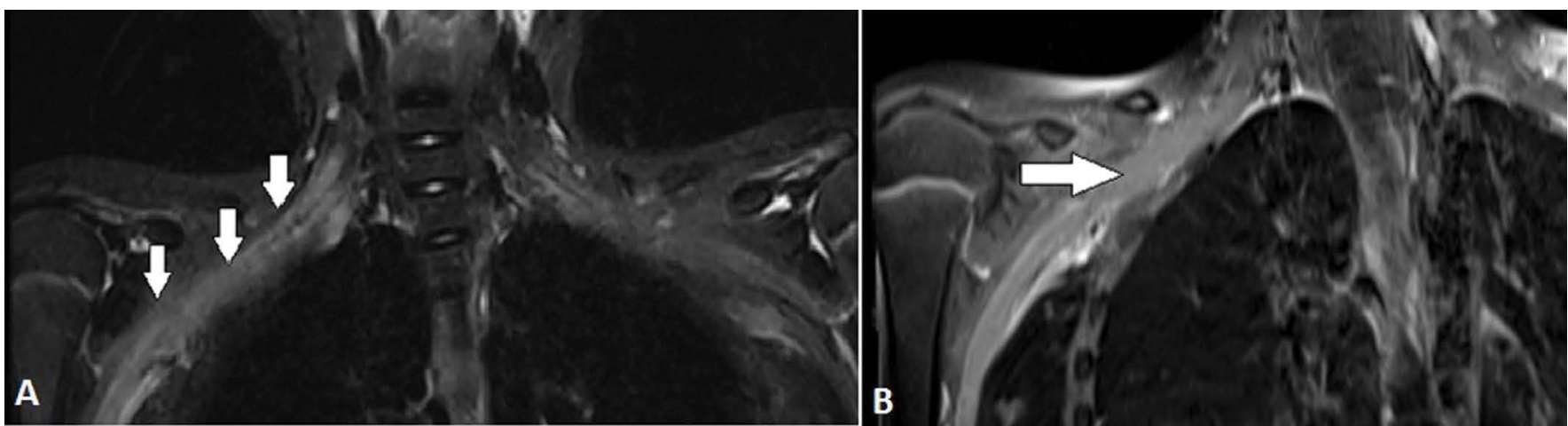

Figure 16: A 12-year-old female, known case of acute lymphocytic leukemia (ALL) with perineural leukemic infiltration of BP. A, Coronal fat-suppressed T2-weighted MR image shows thickening and clumping of the infraclavicular portion of the right BP leading to loss of normal internal fascicular architecture (arrows). B, Coronal fat-suppressed post contrast T1-weighted MR image shows perineural enhancing tissue along the retro and infraclavicular portion of the right BP (arrow) suggesting leukemic deposits.

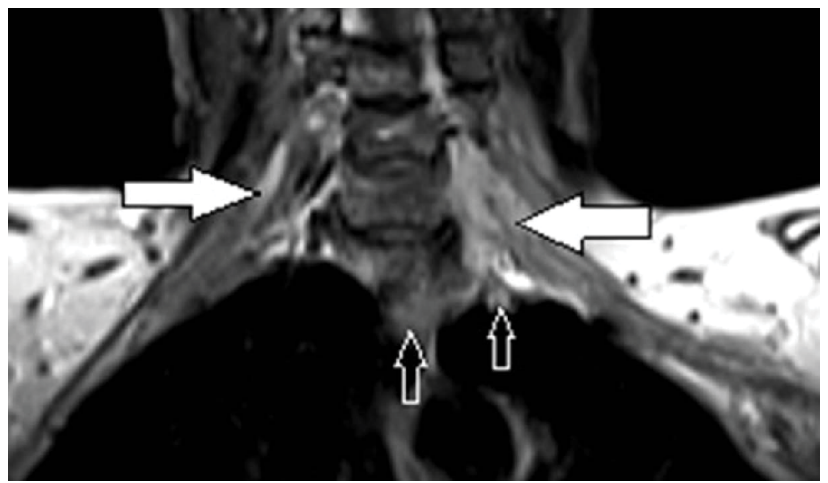

Figure 17: A 65-year-old female with left superior sulcus metastatic breast carcinoma with diffuse BP involvement. Coronal post contrast T1-weighted MR image shows infiltrative enhancing soft tissue along the BP (solid arrows) bilaterally, left $>$ right. On the left side, this enhancing soft tissue extending from left lung apex (open arrows) to BP.

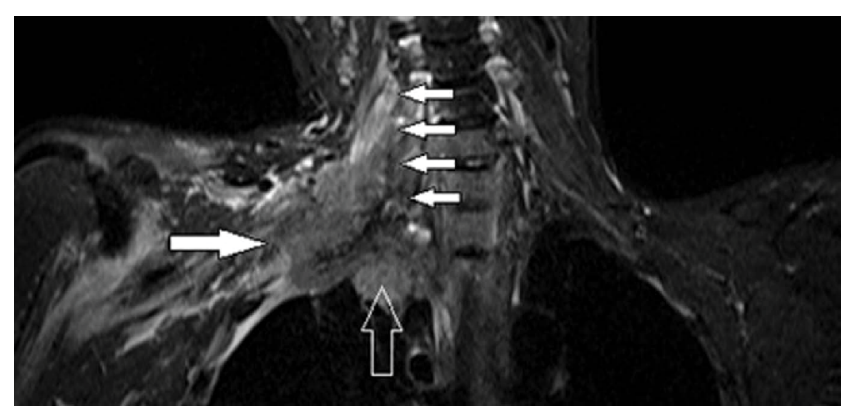

Figure 18: A 62-year-old male with Pancoast tumour causing diffuse involvement of BP. Coronal fat-suppressed T2-weighted MR image shows iso to hyperintense mass in the right lung apex (open arrow) with diffuse infiltration of right BP (solid arrows).

(Figure 16A and 16B). The clinical improvement after treatment with chemotherapy further confirms the diagnosis.

\section{Diffuse metastatic plexopathy}

Patients with metastatic plexopathy present with either isolated lower trunk or diffuse involvement of the BP. Usually malignant infiltration of the plexus results from contiguous structures such as axillary or supraclavicular nodes or by apical tumours of the lung (Figure 17). In metastatic plexopathy pain is usually the first symptom and often precedes neurologic deficits. Pancoast tumour generally involves the lower BP (C7, C8, T1) but can also involve the upper plexus $(\mathrm{C} 5, \mathrm{C} 6)$ as a part of panplexopathy seen in extensively infiltrating tumours (Figure 18) [21]. On imaging enhancing infiltrative multifocal soft tissue masses along the BP can be seen [22].

\section{Conclusion}

MRI is an excellent imaging tool for the evaluation of BP pathology. Awareness of the broad spectrum of pathologies and their clinical presentation along with accurate localization and identification of specific imaging features on MR helps in the diagnosis of various conditions affecting the BP.

\section{References}

1. Sureka J, Cherian RA, Alexander M, Thomas BP (2009) MRI of brachial plexopathies. Clin Radiol 64: 208-218.

2. Todd M, Shah GV, Mukherji SK (2004) MR imaging of brachial plexus. Top Magn Reson Imaging 15: 113-125.

3. Bowen BC, Pattany PM, Saraf-Lavi E, Maravilla KR (2004) The brachial plexus: normal anatomy, pathology, and MR imaging. Neuroimaging Clin N Am 14: 5985, vii-viii.

4. Castillo M (2005) Imaging the anatomy of the brachial plexus: review and selfassessment module. AJR Am J Roentgenol 185: S196-204.

5. Agur Anne MR, Dalley AF (2005) Neck Prevertebral region. Grant's atlas of anatomy. (11thedn) Lippincott Williams \& Wilkins, Baltimore, MD, 761-763.

6. Johnson D, Ellis H (2005) Pectoral girdle and upper limb. The anatomical basis of clinical practice (39th edn). Elsevier, Philadelphia 846-849.

7. Castagno AA, Shuman WP (1987) MR imaging in clinically suspected brachial plexus tumor. AJR Am J Roentgenol 149: 1219-1222.

8. Flores LP, Carneiro JZ (2007) Peripheral nerve compression secondary to adjacent lipomas. Surg Neurol 67: 258-262.

9. Kransdorf MJ, Murphey MD (1997) Neurogenic tumors. Imaging of soft tissue tumors. Philadelphia, Pa: Saunders: 235-273.

10. Stull MA, Moser RP Jr, Kransdorf MJ, Bogumill GP, Nelson MC (1991) Magnetic resonance appearance of peripheral nerve sheath tumors. Skeletal Radiol 20 9-14.

11. Beaman FD, Kransdorf MJ, Menke DM (2004) Schwannoma: radiologicpathologic correlation. Radiographics 24: 1477-1481.

12. Koga H, Matsumoto S, Manabe J, Tanizawa T, Kawaguchi N (2007) Definition 
Citation: Panwar JS, Jakkani RK, Thomas BP (2015) TMR Imaging of Non-Traumatic Intrinsic Brachial Plexus Neuropathy: Spectrum of Findings. J Nucl Med Radiat Ther 5: 246. doi:10.4172/2155-9619.1000246

of the target sign and its use for the diagnosis of schwannomas. Clin Orthop Relat Res 464: 224-229.

13. Pilavaki M, Chourmouzi D, Kiziridou A, Skordalaki A, Zarampoukas T, et al (2004) Imaging of peripheral nerve sheath tumors with pathologic correlation: pictorial review. Eur J Radiol 52: 229-239.

14. Friedrich RE, Kluwe L, Funsterer C, Mautner VF (2005) Malignant peripheral nerve sheath tumors (MPNST) in neurofibromatosis type 1 (NF1): diagnostic findings on magnetic resonance images and mutation analysis of the NF1 gene. Anticancer Res 25: 1699-16702.

15. Tacconi L, Thom M, Thomas DG (1996) Primary monophasic synovial sarcoma of the brachial plexus: report of a case and review of the literature. Clin Neurol Neurosurg 98: 249-252.

16. Zenmyo M, Komiya S, Hamada T, Hiraoka K, Nagata K, et al. (2001) Intraneura monophasic synovial sarcoma: a case report. Spine (Phila Pa 1976) 26: 310 313.

17. Chesser TJ, Geraghty JM, Clarke AM (1999) Intraneural synovial sarcoma of the median nerve. J Hand Surg Br 24: 373-375.

18. Meller I, Alkalay D, Mozes M, Geffen DB, Ferit T (1995) Isolated metastases to peripheral nerves. Report of five cases involving the brachial plexus. Cancer 76: $1829-1832$.

19. Grant PE, Gallagher J, Gonzalez RG, Borsook D (2008) Adriamycin injection into the medial cord of the brachial plexus: computed tomography-guided targeted pain therapy. Pain Med 9: 83-87.

20. Wittenberg KH, Adkins MC (2000) MR imaging of nontraumatic brachial plexopathies: frequency and spectrum of findings. Radiographics 20: 10231032.

21. Heelan RT, Demas BE, Caravelli JF, Martini N, Bains MS, et al. (1989) Superior sulcus tumors: CT and MR imaging. Radiology 170: 637-641.

22. McLoud TC, Filion RB, Edelman RR, Shepard JA (1989) MR imaging of superior sulcus carcinoma. J Comput Assist Tomogr 13: 233-239.

23. Cortes W, Cheng J, Matloub HS (2005) Intraneural perineurioma of the radial nerve in a child. J Hand Surg Am 30: 820-825

24. Lee DH and Dick HM (1998) Management of peripheral nerve tumors. Management of peripheral nerve problems (2nd edn). WB Saunders Company. Philadelphia 597-614.

25. Gorson KC, Ropper AH, Weinberg DH (1999) Upper limb predominant, multifocal chronic inflammatory demyelinating polyneuropathy. Muscle Nerve 22: 758-765

26. Thomas PK, Claus D, Jaspert A, Workman JM, King RH, et al. (1996) Focal upper limb demyelinating neuropathy. Brain 119: 765-774.
27. Bradley LJ, Wilhelm T, King RH, Ginsberg L, Orrell RW (2006) Brachial plexus hypertrophy in chronic inflammatory demyelinating polyradiculoneuropathy Neuromuscul Disord 16:126-131.

28. Choi SK, Bowers RP, Buckthal PE (1990) MR imaging in hypertrophic neuropathy: a case of hereditary motor and sensory neuropathy, type (Charcot-Marie-Tooth). Clin Imaging 14: 204-207.

29. Cellerini M, Salti S, Desideri V, Marconi G (2000) MR imaging of the cauda equina in hereditary motor sensory neuropathies: correlations with sural nerve biopsy. AJNR Am J Neuroradiol 21: 1793-1798.

30. Kale HA, Sklar E (2007) Magnetic resonance imaging findings in chronic inflammatory demyelinating polyneuropathy with intracranial findings and enhancing, thickened cranial and spinal nerves. Australas Radiol 51: 21-24.

31. Midroni G, de Tilly LN, Gray B, Vajsar J (1999) MRI of the cauda equina in CIDP: clinical correlations. J Neurol Sci 170: 36-44.

32. Duarte J, Martinez AC, Rodriguez F, Mendoza A, Sempere AP, et al. (1999) Hypertrophy of multiple cranial nerves and spinal roots in chronic inflammatory demyelinating neuropathy. J Neurol Neurosurg Psychiatry 67: 685-687.

33. Bowen BC, Verma A, Brandon AH, Fiedler JA (1996) Radiation-induced brachia plexopathy: MR and clinical findings. AJNR Am J Neuroradiol 17: 1932-1936.

34. Bagley FH, Walsh JW, Cady B, Salzman FA, Oberfield RA, et al. (1978) Carcinomatous versus radiation-induced brachial plexus neuropathy in breast cancer. Cancer 41: 2154-2157.

35. Kori SH, Foley KM, Posner JB (1981) Brachial plexus lesions in patients with cancer: 100 cases. Neurology 31: 45-50.

36. Pascual-Castroviejo I, Pascual-Pascual SI, Viaño J, Martinez V (2000) Generalized nerve sheath tumors in neurofibromatosis type 1 (NF1). A case report. Neuropediatrics 31: 211-213.

37. Pietrangeli A, Milella M, De Marco S, Bartolazzi A, Mottolese M, et al. (2000) Brachial plexus neuropathy as unusual onset of diffuse neurolymphomatosis. Neurol Sci 21: 241-245.

38. Misdraji J, Ino Y, Louis DN, Rosenberg AE, Chiocca EA, et al. (2000) Primary lymphoma of peripheral nerve: report of four cases. Am J Surg Pathol 24: 1257 1265.

39. Liang R, Kay R, Maisey MN (1985) Brachial plexus infiltration by non-Hodgkin's lymphoma. Br J Radiol 58: 1125-1127.

40. Diaz-Arrastia R, Younger DS, Hair L, Inghirami G, Hays AP, et al. (1992) Neurolymphomatosis: a clinicopathologic syndrome re-emerges. Neurology 42: $1136-1141$.

41. Baker SK, Lipson DM (2010) Vincristine-induced peripheral neuropathy in a neonate with congenital acute lymphoblastic leukemia. J Pediatr Hematol Oncol 32: e114-117. 